\title{
An assessment of the microbiological quality of liver-based pâté in England 2012-13: comparison of samples collected at retail and from catering businesses
}

\author{
J. McLAUCHLIN ${ }^{1,2}$, F. JØRGENSEN ${ }^{3}$, H. AIRD ${ }^{4}$, A. CHARLETT ${ }^{5}$, N. ELVISS $^{6}$, \\ D. FENELON ${ }^{7}$, A. FOX ${ }^{8}$, C. WILLIS ${ }^{3}$ AND C. F. L. AMAR ${ }^{9}$ \\ ${ }^{1}$ Public Health England Food, Water and Environmental Microbiology Services, London NW9 5EQ, UK \\ ${ }^{2}$ University of Liverpool, Institute of Infection and Global Health, UK \\ ${ }^{3}$ Public Health England Food, Water and Environmental Microbiology Laboratory Porton, Porton Down, \\ Salisbury SP4 0JG, UK \\ ${ }^{4}$ Public Health England Food, Water and Environmental Microbiology Laboratory York, National Agri-Food \\ Innovation Campus, York, YO41 1LZ, York, UK \\ ${ }^{5}$ Public Health England Statistics, Modelling and Economics Department, 61 Colindale Avenue, London NW9 \\ $5 E Q, U K$ \\ ${ }^{6}$ Public Health England Food, Water and Environmental Microbiology Laboratory London, Colindale, London \\ NW9 5EQ, UK \\ ${ }^{7}$ Public Health England Food, Water and Environmental Microbiology Laboratory Birmingham, Good Hope \\ Hospital, Sutton Coldfield, B75 7RR, UK \\ ${ }^{8}$ Public Health England Food, Water and Environmental Microbiology Laboratory Preston, Royal Preston \\ Hospital, Preston PR2 9HT, UK \\ ${ }^{9}$ Gastrointestinal Bacteria Reference Unit, Public Health England, Colindale, London NW9 5EQ, UK
}

Received 21 October 2016; Final revision 21 December 2016; Accepted 28 December 2016; first published online 13 February 2017

\section{SUMMARY}

The purpose of this study was to investigate the microbiological quality of liver pâté. During 2012-13, a total of 870 samples, unrelated to the investigation of food-poisoning outbreaks, were collected either at retail $(46 \%)$, catering $(53 \%)$ or the point of manufacture $(1 \%)$ and were tested using standard methods to detect Salmonella spp. or Campylobacter spp., and to enumerate for Listeria spp., including Listeria monocytogenes, Clostridium perfringens, coagulase-positive staphylococci including Staphylococcus aureus, Bacillus spp., including Bacillus cereus, Escherichia coli, Enterobacteriaceae, and aerobic colony counts (ACCs). Seventy-three percent of samples were of satisfactory microbiological quality, $18 \%$ were borderline and $9 \%$ unsatisfactory. Salmonella spp. or Campylobacter spp. was not recovered from any sample. The most common causes of unsatisfactory results were elevated ACCs (6\% of the samples) and high Enterobacteriaceae counts ( $4 \%$ of samples). The remaining unsatisfactory results were due to elevated counts of: $E$. coli (three samples); B. cereus (one sample at $2.6 \times 10^{5} \mathrm{cfu} / \mathrm{g}$ ); or L. monocytogenes (one sample at $2.9 \times 10^{3} \mathrm{cfu} / \mathrm{g}$ ). Pâté from retail was less likely to be contaminated with $L$. monocytogenes than samples collected from catering and samples from supermarkets were of significantly better microbiological quality than those from catering establishments.

Key words: Foodborne illness, foodborne pathogens, indicator organisms, liver pâté, microbiological quality.

\footnotetext{
* Author for correspondence: J. McLauchlin, Public Health England, 61 Colindale Ave, London NW9 5EQ, UK. (Email: Jim.mclauchlin@phe.gov.uk)
} 


\section{INTRODUCTION}

Pâté is a food prepared from a minced mixture of offal (particularly liver), muscle, fat, vegetables, herbs and spices which is cooked at relatively low temperatures [1]. A variety of constituents from different animal species are used in pâté production, particularly pigs or poultry (e.g. chickens and ducks), although fish and shellfish can also be used. Following a period of chilling, pâté is usually served as a ready-to-eat spreadable paste, often together with bread or other farinaceous products. The major risks from microbiological hazards for liver pâté consumption are associated with the low cooking temperatures (including the possibility of undercooking), contamination after cooking and the growth of bacteria in the product during storage. In England and Wales in the 1980s, outbreaks of food poisoning caused by the consumption of liver pâté were associated with Listeria monocytogenes [2] and Salmonella [3]. More recently there has been an increase in liver pâté outbreaks associated with Campylobacter [4-6] in England and Wales, as well as in other countries [7-10]. Outbreaks of foodborne illness associated with pâté consumption outside the UK have also been reported due to botulism [11], hepatitis A virus [12] and Aeromonas hydrophila [13].

A previous report [14] detected differences in the microbiological quality of in-house made pâté as compared with that produced on a larger commercial scale. However, there are no recent data to support this observation. Therefore, in addition to the increase in outbreaks due to Campylobacter and the lack of recent data on microbiological quality, this study was undertaken to provide an assessment of the microbiological quality of liver pâté from catering and retail settings and allow comparison of in-house and large scale produced product.

\section{METHODS}

\section{Sample collection}

Samples of ready-to-eat pâté with liver as the major ingredient were collected during April 2012 to March 2013, and all were independent of any outbreak investigations or incidents associated with foodborne illness. Sampling officers from Environmental Health Departments in England collected liver pâté either from retail (national supermarkets, butchers, delicatessens, farm-shops, and other small- and medium-sized retailers), from catering (public houses, cafes, restaurants, hotels, guest houses, mobile food units and takeaways), or from the point of manufacture where this was separate to the point of sale or serving. Data on temperature of storage were collected by the sampling officer as outlined in the Food Standards Agency Food Law Practice Guidance [15]. Initially, temperature of storage data were obtained by an assessment of the food business operator's own refrigeration equipment. The specific temperature of storage was collected either via an external/surface thermometer or via the food business operator's or the sampling officer's own temperature probe. Information on retailer, vendor or caterer, the sample type, country of origin and details of the storage at the point of sale were collected by the sampling officers: data were collected using a standardised study questionnaire.

At least $100 \mathrm{~g}$ of pâté was sampled and transported in accordance with the Food Standards Agency Food Law Practice Guidance [15]. All samples were examined by one of the five Health Protection Agency (HPA) Official Control Laboratories in England (Food, Water and Environmental Microbiology Laboratories) located at Birmingham, London, Preston, Porton and York

\section{Microbiological examination}

Pâté samples were examined using internationally recognised standard methods. These comprised: detection of Salmonella spp. (BS EN ISO 6579:2002); detection of Campylobacter spp. (ISO 10272-1:2006); detection and enumeration of Listeria spp., including L. monocytogenes (BS EN ISO 11290-1:1996 and 11290-2:1998); enumeration of Clostridium perfringens (ISO 7937:2004); enumeration of coagulase-positive staphylococci, including Staphylococcus aureus (BS EN ISO 6888-1:1999 + A1:2003); enumeration of Bacillus spp., including Bacillus cereus (BS EN ISO 7932:2004); enumeration of Escherichia coli (based on BS ISO 16649-2:2001 but using a surface spread rather than pour plate technique); enumeration of Enterobacteriaceae (BS EN ISO 21528-2 2004); enumeration of aerobic colony counts (ACCs; BS 4833-2:2013). All presence/absence tests were performed on $25 \mathrm{~g}$ samples.

The identification of isolates of Bacillus spp., $C$. perfringens, $L$. monocytogenes and $S$. aureus was performed in each of the individual laboratories as outlined in the standard methods above. Cultures of $L$. monocytogenes were sent to the HPA GBRU (Gastrointestinal Bacteria Reference Unit), for 
Table 1. Criteria for the interpretation of microbiology results (Health Protection Agency, 2009 [20])

\begin{tabular}{|c|c|c|c|c|}
\hline & Satisfactory & Borderline & Unsatisfactory & $\begin{array}{l}\text { Unsatisfactory: } \\
\text { potentially injurious } \\
\text { to health }\end{array}$ \\
\hline & \multicolumn{4}{|c|}{$\mathrm{cfu} / \mathrm{g}$} \\
\hline Bacillus spp. including B. cereus & $<10^{3}$ & $\geqslant 10^{3}-<10^{5}$ & N/A & $\geqslant 10^{5}$ \\
\hline Campylobacter spp. & Absent & N/A & N/A & Detected \\
\hline C. perfringens & $<10$ & $\geqslant 10-10^{4}$ & N/A & $\geqslant 10^{4}$ \\
\hline L. monocytogenes & $<20$ & $\geqslant 20-<100$ & N/A & $\geqslant 10^{2 *}$ \\
\hline Listeria spp. (not L. monocytogenes) & $<20$ & $\geqslant 20-<100$ & $\geqslant 100$ & N/A \\
\hline Salmonella spp. & Absent & N/A & N/A & Detected* \\
\hline S. aureus and other coagulase-positive staphylococci & $<20$ & $\geqslant 20-<10^{4}$ & N/A & $\geqslant 10^{4}$ \\
\hline E. coli & $<20$ & $\geqslant 20-<10^{2}$ & $\geqslant 10^{2}$ & N/A \\
\hline Enterobacteriaceae & $<10^{2}$ & $\geqslant 10^{2}-10^{4}$ & $\geqslant 10^{4}$ & N/A \\
\hline \multicolumn{5}{|l|}{$A C C$} \\
\hline Category $5 \dagger$ & $<10^{5}$ & $\geqslant 10^{5}-<10^{7}$ & $\geqslant 10^{7}$ & N/A \\
\hline
\end{tabular}

N/A, not applicable.

* Exceeds limits in EC Regulation No. 2073/2005 [21].

$\dagger$ As defined in Health Protection Agency, 2009 [20].

confirmation and further characterisation [16-19]. Comparison of L. monocytogenes types was carried out using the UK national surveillance database of results generated from analysis of isolates from both human cases of listeriosis and food.

Microbiological results were interpreted according to the HPA Guidelines for assessing the microbiological safety of ready-to-eat foods placed on the market as outlined in Table 1 [20] to categorise the results as unsatisfactory, borderline, and satisfactory. Regulation (European Commission, EC) No. 2073/2005 on microbiological criteria for foodstuffs [21] was also used to interpret microbiological results where relevant. Samples for which results were not available for one or more of the microbiological parameters specified in the study protocol were excluded from this analysis.

\section{Statistical analysis}

Contingency tables were used to provide both descriptive and inferential analysis of the study data. Initially $\chi^{2}$ tests were performed to assess associations between variables collected on the sample and microbiological quality. The microbiological outcome of the ordered categorical variable; satisfactory, borderline and unsatisfactory was used in an ordered logistic regression analysis to quantify the strength of association in terms of estimated relative odds. These refer to a specific outcome category compared with the category immediately lower, e.g. the odds of satisfactory compared with the odds of borderline. The assumption of proportional odds was assessed to ensure the validity that the odds ratio across all categories as approximately equal. A $P$ value of 0.05 or lower was defined as indicating statistical significance. All analyses were performed using Stata v 13 (Stata Corp. College Station, Texas).

\section{RESULTS}

A total of 870 liver pâté samples were tested: data from a further 56 samples were submitted but these were not included in the analysis since results from one or more of the microbiological parameters specified in the study protocol were missing. Following interpretation according to the HPA Guidelines for assessing the microbiological safety of ready-to-eat foods [20], 73\% were of satisfactory microbiological quality, $18 \%$ were borderline and $9 \%$ were unsatisfactory (Table 2). Neither Salmonella spp. nor Campylobacter spp. was isolated from any sample. The most common causes of unsatisfactory results were elevated ACCs ( $6 \%$ of the samples) and high Enterobacteriaceae counts (5\% of samples). The remaining unsatisfactory results were due to elevated counts of either $E$. coli (three samples), B. cereus (one sample at $2.6 \times 10^{5} \mathrm{cfu} / \mathrm{g}$ ) or $L$. monocytogenes (one sample at $2.9 \times 10^{3} \mathrm{cfu} / \mathrm{g}$ ). Amongst the $18 \%$ of samples that were of borderline quality, the commonest individual causes (in order of numbers of samples) were elevated: ACCs, Enterobacteriaceae, Bacillus spp., E. coli, B. cereus, S. aureus, C. perfringens and L. monocytogenes (Table 2). L. monocytogenes at $<20 \mathrm{cfu} / \mathrm{g}$ was 
Table 2. Microbiological quality of 870 ready-to-eat pâté by different parameters and premises types

\begin{tabular}{|c|c|c|c|c|}
\hline & \multicolumn{4}{|c|}{ Number of pâté samples } \\
\hline & Total & Satisfactory & Borderline & Unsatisfactory \\
\hline All samples & 870 & $633(73 \%)$ & $158(18 \%)$ & $79(9 \%)$ \\
\hline \multicolumn{5}{|l|}{ Microbiological parameter } \\
\hline B. cereus/g & 870 & $861(99 \%)$ & $8(1 \%)$ & 1 \\
\hline Other Bacillus spp. & 870 & $847(97 \%)$ & $23(3 \%)$ & 0 \\
\hline Campylobacter spp. & 870 & $870(100 \%)$ & 0 & 0 \\
\hline C. perfringens & 870 & $868(99 \%)$ & 2 & 0 \\
\hline L. monocytogenes & $870^{*}$ & $867(99 \%)$ & 2 & 1 \\
\hline Listeria spp. (not L. monocytogenes) & $870^{\dagger}$ & $870(100 \%)$ & 0 & 0 \\
\hline Salmonella spp. & 870 & $870(100 \%)$ & 0 & 0 \\
\hline S. aureus & 870 & $862(99 \%)$ & $8(1 \%)$ & 0 \\
\hline E. coli & 870 & $856(98 \%)$ & $11(1 \%)$ & 3 \\
\hline Enterobacteriaceae & 870 & $761(87 \%)$ & $69(8 \%)$ & $40(5 \%)$ \\
\hline ACC & 870 & $692(79 \%)$ & $127(15 \%)$ & $51(6 \%)$ \\
\hline \multicolumn{5}{|l|}{ Type of setting } \\
\hline Catering (total) & 399 & $271(68 \%)$ & $87(22 \%)$ & $41(10 \%)$ \\
\hline Restaurants and cafes & 190 & $132(69 \%)$ & $37(19 \%)$ & $21(11 \%)$ \\
\hline Public houses & 120 & $79(66 \%)$ & $33(27 \%)$ & $8(7 \%)$ \\
\hline Hotels and guest houses & 83 & $58(70 \%)$ & $15(18 \%)$ & $10(12 \%)$ \\
\hline Other catering & 6 & $2(33 \%)$ & $2(33 \%)$ & $2(33 \%)$ \\
\hline Retail supermarkets & 283 & $232(82 \%)$ & $36(13 \%)$ & $15(5 \%)$ \\
\hline Other retail (total) & 179 & $124(69 \%)$ & $34(19 \%)$ & $21(12 \%)$ \\
\hline Delicatessens & 61 & $37(60 \%)$ & $15(25 \%)$ & $9(15 \%)$ \\
\hline Butchers & 39 & $24(62 \%)$ & $7(18 \%)$ & $8(20 \%)$ \\
\hline Other shops ${ }^{\S}$ & 79 & $63(80 \%)$ & $12(15 \%)$ & $4(5 \%)$ \\
\hline Manufacturers & 9 & $6(66 \%)$ & $1(11 \%)$ & $2(22 \%)$ \\
\hline \multicolumn{5}{|l|}{ Declared major meat constituent } \\
\hline Chicken & 349 & $251(72 \%)$ & $64(18 \%)$ & $34(10 \%)$ \\
\hline Pork & 266 & $209(79 \%)$ & $38(14 \%)$ & $19(7 \%)$ \\
\hline Duck & 82 & $53(65 \%)$ & $20(24 \%)$ & $9(11 \%)$ \\
\hline Other (including mixtures) & 57 & $43(75 \%)$ & $9(16 \%)$ & $5(9 \%)$ \\
\hline NK & 116 & $77(66 \%)$ & $27(23 \%)$ & $12(10 \%)$ \\
\hline
\end{tabular}

NK, not known.

* L. monocytogenes detected in 10 samples including two samples categorised as borderline where the bacterium was present at 40 and $80 \mathrm{cfu} / \mathrm{g}$ and one sample categorised as unacceptable where the bacterium was present at $2 \cdot 9 \times 10^{3} \mathrm{cfu} / \mathrm{g}$ and is potentially injurious to health.

$\dagger$ Listeria spp. detected in nine samples, six L. welshimeri, two L. seeligeri, 1 L. innocua.

* Four samples from mobile vendors and two from takeaways.

$\S$ Sixteen from farm shops, 6 from market stalls and 17 from other shops.

recovered from a further seven samples, and nine samples contained Listeria spp. (not L. monocytogenes) also at $<20 \mathrm{cfu} / \mathrm{g}$. The sample containing $L$. monocytogenes at $>10^{2} \mathrm{cfu} / \mathrm{g}$ was the only sample that did not comply with the microbiological criteria as laid down in EC Regulation No. 2073 [21].

\section{Samples from catering, retail and manufacture}

Samples from catering (those where liver pâté was served for direct consumption by consumers) included public houses, cafes, restaurants, hotels, guest houses, mobile food units and takeaways. Retail establishments (those where liver pâté was sold for consumption elsewhere) included national supermarkets, butchers, delicatessens, farm-shops, and other small- and medium-sized retailers. The point of manufacture was included where this was separate to the point of sale or serving. Amongst all 870 samples, $46 \%$ were from catering, 53\% were from retail and the remaining 1\% were from the point of manufacture. The 399 samples from catering were collected from: restaurants and cafés $(48 \%)$, public houses $(30 \%)$, hotels and guest houses $(21 \%)$ and the remainder from mobile vendors 
Table 3. Temperature of storage for 318 samples of pâte at the point of collection

\begin{tabular}{|c|c|c|c|c|}
\hline & \multicolumn{4}{|c|}{ Numbers of pâté samples } \\
\hline & Total & Satisfactory & Borderline & Unsatisfactory \\
\hline \multicolumn{5}{|l|}{ Frozen $(n=16)$} \\
\hline Catering & 10 & $9(90 \%)$ & 0 & $1(10 \%)$ \\
\hline \multicolumn{5}{|l|}{ Retail } \\
\hline National supermarkets & 0 & & & \\
\hline Other retailers & 6 & $6(100 \%)$ & 0 & 0 \\
\hline \multicolumn{5}{|c|}{ Refrigerated $0-<8{ }^{\circ} \mathrm{C}(n=248)$} \\
\hline Catering & 94 & $67(71 \%)$ & $19(20 \%)$ & $8(9 \%)$ \\
\hline Retail (total) & 154 & $128(83 \%)$ & $18(12 \%)$ & $8(5 \%)$ \\
\hline National supermarkets & 109 & $96(88 \%)$ & $10(9 \%)$ & $3(3 \%)$ \\
\hline Other retailers & 45 & $32(71 \%)$ & $8(18 \%)$ & $5(11 \%)$ \\
\hline \multicolumn{5}{|c|}{ Refrigerated $\geqslant 8-22{ }^{\circ} \mathrm{C}(n=54)$} \\
\hline Catering & 33 & $22(67 \%)$ & $8(24 \%)$ & $3(9 \%)$ \\
\hline Retail (total) & 21 & $19(90 \%)$ & $2(10 \%)$ & 0 \\
\hline National supermarkets & 10 & $9(90 \%)$ & $1(10 \%)$ & 0 \\
\hline Other retailers & 11 & $10(91 \%)$ & $1(9 \%)$ & 0 \\
\hline
\end{tabular}

or takeaways $(1 \%)$. Amongst the 462 pâté samples from retail, $61 \%$ were from national retail chain supermarkets, $13 \%$ from delicatessens, $8 \%$ from butchers and $17 \%$ from other shops (farm shops, market stalls and other types of retailers). An ordered logistic regression model was employed to assess differences in microbiological quality between samples from catering, retail supermarkets and other retail settings, and the likelihood ratio test showed a significant difference $\left(\chi^{2}\right.$ test $13 \cdot 2$ on 2 degrees of freedom, $P=0 \cdot 001)$. The microbiological quality of pâté sampled from supermarkets was significantly better than those from catering establishments (odds ratio 0.57, 95\% CI 0.40-0.84, $P=$ $0.004)$ : there were no significant differences between the results obtained from pâté collected from catering with those from other retailers.

An ordered logistic regression model was employed to assess if there was evidence for differences in microbiological quality between results from samples collected from within all catering and all retail settings. Within catering, the microbiological quality of samples from mobile vendors and from takeaways was significantly worse than those from restaurant and café establishments (95\% CI 1.00-20.62, $P=0.05$ ). There were no significant differences in sample microbiological quality between all other catering settings. For samples from different retail settings, the likelihood ratio test showed a significant difference $\left(\chi^{2}\right.$ test 19.04 on 3 degrees of freedom, $P=0.0003$ ). Samples from delicatessens were of significantly worse microbiological quality than those from supermarkets (estimated odds ratio $2 \cdot 95 \quad 95 \%$ CI $1 \cdot 65-5 \cdot 29, P<0 \cdot 001)$. The microbiological quality of samples from butchers was significantly worse than those from supermarkets (estimated odds ratio $3 \cdot 14$, $95 \%$ CI $1 \cdot 55-6 \cdot 37, P=0 \cdot 001)$. Comparison of results for samples from all other retail settings showed no significant differences in microbiological quality.

\section{Declared animal species used for liver}

Amongst all 870 samples, the most common declared animal species used for liver was chicken in $40 \%$, pork in $31 \%$, duck in $9 \%$ and other animals (including mixtures) was declared for 7\%: information was not available in the remaining 13\% (Table 2). An ordered logistic regression model showed that there was a significant difference in the quality between the declared animal species $\left(\chi^{2}\right.$ test statistics $9 \cdot 43$ on 4 degrees of freedom, $\left.P=0 \cdot 05\right)$. The microbiological quality of pork liver pâté was significantly better than that of poultry (chicken and duck; estimated odds ratio was $0 \cdot 66,95 \%$ CI $0 \cdot 46-0 \cdot 94$, $P=0 \cdot 02$ ). For all other comparisons between pâté manufactured from the livers of different animal species there were no significant differences in sample quality and this effect was independent of the setting.

\section{Temperature of storage}

Data on specific temperature of storage were available for $318(37 \%)$ of all samples (Table 3) and 5\% were stored frozen, $78 \%$ were recorded as between 0 and 
Table 4. Remaining shelf-life data for 176 samples of refrigerated pâté

\begin{tabular}{|c|c|c|c|c|c|c|c|c|c|c|}
\hline \multirow[b]{3}{*}{ Shelf life in days } & \multicolumn{9}{|c|}{ Number of samples } & \multirow[b]{3}{*}{ Totals } \\
\hline & \multicolumn{3}{|c|}{ Catering $(n=79)$} & \multicolumn{3}{|c|}{$\begin{array}{l}\text { Retail, supermarkets } \\
(n=65)\end{array}$} & \multicolumn{3}{|c|}{ Retail, other $(n=32)$} & \\
\hline & $\mathrm{S}$ & $\mathrm{B}$ & $\mathrm{U}$ & $\mathrm{S}$ & B & $\mathrm{U}$ & $\mathrm{S}$ & $\mathrm{B}$ & $\mathrm{U}$ & \\
\hline $0-5$ & 38 & 14 & 12 & 9 & 0 & 1 & 3 & 2 & 1 & 80 \\
\hline $6-10$ & 1 & 1 & 0 & 4 & 0 & 1 & 4 & 1 & 1 & 13 \\
\hline $11-20$ & 1 & 0 & 0 & 18 & 4 & 1 & 0 & 1 & 0 & 25 \\
\hline $21-30$ & 3 & 0 & 0 & 8 & 1 & 0 & 2 & 1 & 1 & 16 \\
\hline $31-40$ & 2 & 2 & 0 & 4 & 0 & 0 & 4 & 1 & 0 & 13 \\
\hline$>40 *$ & 4 & 1 & 0 & 13 & 1 & 0 & 10 & 0 & 0 & 29 \\
\hline
\end{tabular}

$\mathrm{S}$, satisfactory; B, borderline; $\mathrm{U}$, unsatisfactory.

* Range 41-211 days, of all 29 samples, eight had a remaining shelf life of $>100$ days.

$<8{ }^{\circ} \mathrm{C}$, and the remaining $17 \%$ were stored at $\geqslant 8-22{ }^{\circ} \mathrm{C}$. In addition, descriptive data were available for 460 $(53 \%)$ of the samples which described these as collected from refrigerated storage. The main effects region model provided estimated odds ratios for microbial quality and there were no significant differences between the quality of samples collected frozen, as compared with those stored refrigerated at $0-<8{ }^{\circ} \mathrm{C}$ and $\geqslant 8-22^{\circ} \mathrm{C}$.

Excluding those stored frozen, the percentage of samples stored at between 0 and $<8^{\circ} \mathrm{C}$ (as compared with those stored at $\geqslant 8{ }^{\circ} \mathrm{C}$ ) was $74 \%$ for catering, $92 \%$ for supermarkets and $80 \%$ for other retail outlets. An ordered logistic regression model was employed to assess whether there was evidence to suggest that the microbiological quality differed between the storage temperature groupings in the different retail settings. The likelihood ratio test was used to provide an overall test of association $\left(\chi^{2}\right.$ test statistics 0.43 on 2 degrees of freedom, $P=0 \cdot 81$ ) and there was no significant difference in the microbiological quality between the storage types. An interaction between the storage groups and retail groups was fitted in the model to assess whether there was any evidence to suggest that the association between storage temperature and microbial quality differed between the retail groups. A likelihood ratio test was used to test this interaction $\left(\chi^{2}\right.$ test statistics 1.51 on 2 degrees of freedom, $P=0.68$ ) and found no evidence for a difference between retail settings.

\section{Remaining shelf life}

For liver pâté made in-house, the shelf-life data collected were the number of days after production before consumption. For commercially produced liver pâté both on retail sale or collected at catering, the remaining shelf life was the time in days between the day of collection and the use-by date on the packaging. Remaining shelf-life data were available for 176 $(20 \%)$ of all the 854 refrigerated samples, and these comprised 79 collected at catering, 65 from supermarkets and 32 from other retail outlets (Table 4). The shelf-life data on the outside of the packaging for samples collected at retail varied from 0 to 211 days. The percentage of samples with a shelf life of 5 or fewer days was $81 \%$ for samples collected at catering, $15 \%$ from supermarkets and 19\% from other retail establishments. Initially each retail group was modelled individually using mid-point of the number of days of shelf life remaining as a continuous predictor variable. In order to assess if the relationship between days of shelf life remaining and microbiological quality was non-linear, the groups were fitted as a categorical predictor, and an ordered logistic regression model was used in this analysis. For samples from catering outlets there was no significant association between days of shelf life remaining and microbiological quality. The likelihood ratio test was used to provide an overall test of association $\left(\chi^{2}\right.$ test statistics $1 \cdot 95$ on 5 degrees of freedom, $P=0 \cdot 86$ ). When considering days of remaining shelf life as a continuous predictor there was no evidence of an association $\left(\chi^{2}\right.$ test statistics 0.03 on 1 degree of freedom, $P=0.87$ ). For samples collected from retail supermarkets, there was no evidence of an association between days of remaining shelf life and microbiological quality. The likelihood ratio test was used to provide an overall test of association $\left(\chi^{2}\right.$ test statistics 1.69 on 5 degrees 
Table 5. Comparison of results for individual microbiological parameters obtained from 234 samples of pâté collected at catering or retail and of borderline or unsatisfactory microbiological quality

\begin{tabular}{|c|c|c|c|c|c|c|}
\hline & \multicolumn{6}{|c|}{ Number of samples } \\
\hline & \multicolumn{2}{|c|}{ Catering $(n=128)$} & \multicolumn{2}{|c|}{$\begin{array}{l}\text { Retail, } \\
\text { supermarkets } \\
(n=51)\end{array}$} & \multicolumn{2}{|c|}{ Other retail $(n=55)$} \\
\hline & $\mathrm{B}$ & $\mathrm{U}$ & $\mathrm{B}$ & $\mathrm{U}$ & $\mathrm{B}$ & $\mathrm{U}$ \\
\hline B. cereus/g & 6 & 1 & 0 & 0 & 2 & 0 \\
\hline Other Bacillus spp. & 8 & 0 & 8 & 0 & 6 & 0 \\
\hline C. perfringens & 2 & 0 & 0 & 0 & 0 & 0 \\
\hline L. monocytogenes* & $1^{\dagger}$ & $1^{*}$ & 0 & 0 & $1^{\ddagger}$ & 0 \\
\hline S. aureus & 6 & 0 & 2 & 0 & 0 & 0 \\
\hline E. coli & 11 & 3 & 0 & 0 & 0 & 0 \\
\hline Enterobacteriaceae & 49 & 21 & 9 & 12 & 11 & 7 \\
\hline $\mathrm{ACC}$ & 63 & 26 & 33 & 6 & 31 & 17 \\
\hline
\end{tabular}

B, borderline; U, unsatisfactory.

* Four samples with L. monocytogenes and five with other Listeria spp. recovered at $<20 \mathrm{cfu} / \mathrm{g}$ were in-house produced and recovered from catering. Three samples contaminated with $L$. monocytogenes at $<20 \mathrm{cfu} / \mathrm{g}$ and collected at retail were all prepackaged and manufactured in Belgium: The four samples from retail contaminated with other Listeria spp. at $<20 \mathrm{cfu} / \mathrm{g}$ three were from supermarkets and one was from a butcher.

$\uparrow$ Produced in-house.

† Pre-packed and produced in another EU Member State.

of freedom, $P=0.89$ ). When considering days of remaining shelf life as a continuous predictor there was again no evidence of an association $\left(\chi^{2}\right.$ test statistics $0 \cdot 17$ on 1 degree of freedom, $P=0 \cdot 68$ ). For other retailers, there was no evidence of an association between days of remaining shelf life and microbiological quality. The likelihood ratio test was used to provide an overall test of association $\left(\chi^{2}\right.$ test statistics 3.89 on 5 degrees of freedom, $P=0.57$ ). When considering days of remaining shelf life as a continuous predictor there was again no evidence of an association $\left(\chi^{2}\right.$ test statistics 1.96 on 1 degree of freedom, $P=0 \cdot 16$ ).

\section{Comparison of results for individual microbiological parameters}

A comparison of results for individual microbiological parameters obtained from 234 samples of pâté collected at retail or from catering which were of borderline or unsatisfactory microbiological quality is shown in Table 5. For B. cereus there was weak evidence to suggest a difference in the percentages where $B$. cereus was present at an unsatisfactory level in slightly more samples from catering than from retail (Fisher's exact test, $P=0 \cdot 07$ ). There was no evidence for differences in the distributions of Bacillus spp., C. perfringens, L. monocytogenes or $S$. aureus between samples collected at retail or from catering which were of borderline or unsatisfactory microbiological quality. There was strong evidence to suggest a difference in the percentages with elevated levels of E. coli and Enterobacteriaceae in catering samples (Fisher's exact test, $P<0.001)$. There was strong evidence to suggest a difference in the percentages where the ACC was considered borderline or unsatisfactory (Fisher's exact test, $P=0.001$ ) in both catering and other retail samples compared with samples from supermarkets. There was a greater proportion of samples contaminated with $L$. monocytogenes from catering as compared with retail ( $1.5 \%$ vs. $0.9 \%)$ : although this was not significantly different (Fisher's exact test, $P=0 \cdot 2$ ), this difference was consistent with the elevated E. coli, Enterobacteriaceae and ACC results from catering establishments outlined above and suggesting poorer hygiene.

\section{Samples contaminated by Listeria including L. monocytogenes}

Amongst the 10 samples contaminated by L. monocytogenes, in all three where this bacterium was detected at $\geqslant 20 \mathrm{cfu} / \mathrm{g}$, borderline Enterobacteriaceae result were obtained. One of the samples where L. monocytogenes was detected at $\geqslant 20 \mathrm{cfu} / \mathrm{g}$ also had an 
Table 6. Characterisation of $\mathrm{L}$. monocytogenes isolates from pâté and comparison with isolates from human cases in the UK (2011-12)

\begin{tabular}{lllll}
\hline \hline Serogroup & fAFLP type & $\begin{array}{l}\text { Levels of } \\
\text { contamination (cfu/g) }\end{array}$ & Collected from & $\begin{array}{l}\text { Numbers of human listeriosis } \\
\text { cases (2011-12) with isolates of } \\
\text { indistinguishable types* }\end{array}$ \\
\hline $1 / 2 \mathrm{a}$ & IX.9 & 80 & Retail (delicatessen) & 2 \\
$1 / 2 \mathrm{a}$ & XIV.42 & $<20$ & Catering (public house) & 2 \\
$1 / 2 \mathrm{a}$ & VIIc.71 & $<20$ & Catering (public house) & 0 \\
$1 / 2 \mathrm{a}$ & IX.14 & $<20$ & Retail (supermarket) & 4 \\
$1 / 2 \mathrm{c}$ & VIIc.46 & 40 & Catering (public house) & 0 \\
$1 / 2 \mathrm{c}$ & VIIc.59 & $2 \cdot 9 \times 10^{3}$ & Catering (public house) & 2 \\
4 & IV4.6 & $<20$ & Catering (public house) & 10 \\
4 & IV4.40 & $<20$ & Catering (public house) & 0 \\
4 & V.7 & $<20$ & Retail (supermarket) & 0 \\
\hline \hline
\end{tabular}

* Total 333 cases of listeriosis.

unsatisfactory ACC. Of the remaining seven samples were L. monocytogenes was present at $<20 \mathrm{cfu} / \mathrm{g}$, three were satisfactory for all other parameters, and of the remaining, two had a borderline Enterobacteriaceae result and three had either an unsatisfactory or borderline ACCs. Six of the samples contaminated by L. monocytogenes were collected from catering establishments (including one of the two borderline results and the one unsatisfactory result) and four were collected at retail. There was no evidence of a significant difference in the percentages where the L. monocytogenes was present in catering compared with retail outlets (Fisher's exact test, $P=0 \cdot 92$ ). Of the six samples from catering contaminated by $L$. monocytogenes, four were chicken and two pork liver pâté and all were collected from public houses and produced in-house, apart from the one sample contaminated at $2 \cdot 9 \times 10^{3} \mathrm{cfu} / \mathrm{g}$ which was manufactured in Belgium and was purchased within 1 day before the end of shelf life. Of the four samples from retail, all were pre-packaged pork liver pâté which were externally manufactured, three were from different Belgian manufacturers (all were obtained from supermarkets) and one was collected from a delicatessen and manufactured in France (L. monocytogenes detected at $80 \mathrm{cfu} / \mathrm{g}$ ): shelf-life data were not available for any of these samples.

Amongst the nine samples contaminated at $<20$ cfu/g by Listeria spp. other than L. monocytogenes, five of these were collected from catering establishments (all were produced in-house and prepared in a hotel, a public house and three restaurants) and the remaining four from retail: three were from supermarkets and one was from a butcher. Amongst these nine samples contaminated with Listeria spp., three where satisfactory for all other parameters. In the remaining six samples: four had a borderline or unsatisfactory Enterobacteriaceae results, one a borderline E. coli and three unsatisfactory or borderline ACCs.

Nine of the $10 \mathrm{~L}$. monocytogenes isolates were tested by molecular serotyping: four were of serogroup $1 / 2 \mathrm{a}$, two $1 / 2 \mathrm{c}$, and the remaining three serogroup 4 (Table 6). Using fluorescent amplified fragment length polymorphism type (fAFLP) analysis, each isolate was characterised as of a distinct type. A comparison was carried out with results from all 333 human listeriosis cases in the UK with onsets during 2011 and 2012 and where L. monocytogenes isolates were submitted for typing. Amongst four of the L. monocytogenes types from pâté, there were no isolates of the same type from any case. Of the remaining five 'pâté types', there were 20 cases (between 2 and 10 cases per type) where isolates were indistinguishable: no epidemiological links were identified with pâté consumption in any of these cases. Furthermore, the one type with the greatest number of cases (fAFLP types IV4.6), comprised two temporal and geographical clusters of five cases each which were consistent with two common source outbreaks associated with sandwich consumption which did not include pâté as a filling.

\section{DISCUSSION}

Outbreaks of food poisoning in England which have been reported in the peer-reviewed literature to have been caused by the consumption of liver pâté were associated with infections due to L. monocytogenes, Salmonella and Campylobacter [2-6]. Furthermore, a 
review was carried out of the Public Health England (PHE) electronic Foodborne and non-Foodborne Gastrointestinal Outbreak Surveillance System (e-FOSS) database which includes a total of 2869 foodborne outbreaks and 71507 cases reported for England between 1992 and 2014. Amongst the reports in the e-FOSS database, 49 outbreaks (814 cases, 2-59 cases per outbreak) were associated with consumption of chicken or duck liver mousse, parfait or pâté. All except 1 of the 49 outbreaks were due to Campylobacter (the remaining outbreak was due to Salmonella Typhimurium) and 48 occurred in catering institutions (universities/colleges, hotels/guest houses, pubs/bars, restaurants and other food service premises). The majority of the Campylobacter outbreaks occurred between 2009 and 2014 (PHE unpublished data).

In this study, a total of 870 liver-based pâté samples were tested as part of a continuing programme of PHE national co-ordinated food studies. This programme involves two to three studies per year and relies on the close working relationship with Environmental Health Departments throughout England to carry out the sampling as part of their routine monitoring. This approach allows sampling officers some flexibility to investigate premises and sample the product types that occur in their local food businesses, rather than being prescriptive about the numbers of each sample type to collect. This approach has been used in previously published studies [e.g. 14, 22-26] and although the sampling strategies are not precisely defined, the study described here presents the results of more than 850 liver pâté samples collected from across all areas of England and throughout each month over an entire year (at least 21 samples were collected each month). Data on the overall consumption of liver pâté were not available in the planning stage of this study (indeed this would be difficult for the in-house prepared products), and we recognise this as a limitation of this study design. However, samples representing the range of retail and catering settings were collected and consequently the data presented here provides a useful overall picture of the microbiological quality of liver pâté products during a 12-month period in 2012-13.

Overall, 870 ready-to-eat pâté samples were tested in this study, and $73 \%$ were classified as of satisfactory microbiological quality, $18 \%$ were borderline and 9\% were unsatisfactory. It is reassuring that the current major hazards associated with liver pâté and identified from surveillance of outbreaks (i.e. Salmonella spp. and Campylobacter spp.), were not isolated from any sample. In addition, for the major hazard previously identified with this food type in the 1980 s (i.e. L. monocytogenes), there was only one $(0 \cdot 1 \%)$ sample with levels of the bacterium considered to be unsatisfactory and potentially injurious to health.

Commercially prepared pork liver pâté was associated with a large outbreak of listeriosis in the 1980s [2] and longitudinal studies performed over the past 25 years have shown a considerable reduction in the occurrence and levels of $L$. monocytogenes detected in the UK $[2,14,22,27]$. Amongst the 10 samples contaminated by L. monocytogenes in this study, six were collected from catering establishments (including one of the two borderline results and the one unsatisfactory result) and four were collected at retail. The single sample collected almost at the end of its shelf life and with $2.9 \times 10^{3} \mathrm{cfu} / \mathrm{g}$ L. monocytogenes demonstrates the continued risk of contamination of the product with harmful levels of this bacterium, albeit that the overall risk is now lower compared with other types of foods. Furthermore, the four samples contaminated with $L$. monocytogenes and collected at retail were all manufactured in other European Union (EU) Member States and comprised pre-packaged pork liver pâté where either the bacterium has survived the cooking process or was present as a result of cross-contamination prior to packaging. This is a further concern since this product can support the growth of L. monocytogenes to levels which are unacceptable and potentially hazardous, even under ideal refrigeration and shelf-life conditions [28] and this includes the range of temperature and remaining shelf lives recorded in this study. The epidemiological and subtyping analysis did not allow the identification of links between consumption of pâté and cases of listeriosis. However, the present surveillance strategies now include whole genome sequencing for the characterisation of $L$. monocytogenes isolates and this will provide the potential for improved identification of associations between infected patients and contaminated foods as well as better recognition of foodborne outbreaks [29].

A previous report from the UK indicated that there were differences in the microbiological quality of in-house produced pâté as compared with that produced on a larger commercial scale [14] and this is supported by the results from this study. Mobile vendors and markets were here identified as more likely to sell foods of borderline or unsatisfactory microbiological quality and this observation is similar to that for other food types [23, 24]. As stated above, 98\% of the foodborne outbreaks associated with pâté 
consumption were from catering outlets. The microbiological quality of pâté sampled from supermarkets was better than those from other retailers. Furthermore, samples from retail were less likely to be contaminated with L. monocytogenes and had lower levels of Enterobacteriaceae and ACCs than those from catering, suggesting poorer hygiene at catering establishments. Neither of these observations could be explained by the types of ingredients and although the temperature control (i.e. proportion of samples stored at $>8{ }^{\circ} \mathrm{C}$ ) was better in supermarkets than in other retail establishments or in catering, this was not reflected in the microbiological quality which was similar in samples stored under different temperatures. It was not possible to identify all those products prepared in-house and those prepared commercially, however, products sold in supermarkets are likely to be commercially prepared in industrial settings with a high degree of control of the process. Products sold at catering, together with those from other retail establishments, are more likely to be prepared in-house and a higher proportion had short shelf lives ( $<6$ days) with poorer microbiological quality suggesting a lower level of control of the hygiene and cooking process. This observation is consistent with the recent data from outbreaks outlined above which identified problems of safety with consumption of liver pâté at catering establishments.

Campylobacter spp., L. monocytogenes and Salmonella spp. occur in raw poultry liver prepared for human consumption [30-32] although Salmonella is likely to be less common in the UK (as well as other parts of the EU) as a result of control programs [33]. These three genera of bacteria will also occur in raw mammalian liver for human consumption, although less commonly than for poultry [34]. In this study there was some evidence that pork liver-based pâtés were of better microbiological quality than those manufactured from poultry livers. Campylobacter spp., L. monocytogenes and Salmonella spp. will be eliminated by proper cooking such as should be applied to pâté [1]. However, as illustrated by data from foodborne outbreaks, undercooking is a major risk factor, particularly for Campylobacter and to a lesser extent Salmonella. Contamination of pâté post-cooking is a risk for all these three groups of pathogens [35] but is of particular concern for $L$. monocytogenes since this hazard can multiply in liver pâté even under ideal refrigerated storage conditions [28]. The presence of $S$. aureus may also provide evidence for contamination post-cooking from food handlers, especially if there are poor practices later in the food chain [36].
Anaerobic and aerobic spore bearing bacteria (e.g. $C$. perfringens and $B$. cereus) are also potential contaminants from the post-cooking environment. However, since $C$. perfringens and $B$. cereus produce endospores and can be present in raw ingredients including those of non-animal origin such as herbs and spices which are commonly added to pâté prior to cooking, these groups of bacteria may survive the cooking process [25].

A previous study carried out by us in 2011 on 356 samples of 'lightly cooked' foods involved testing samples collected after regeneration and as would be served to a consumer [26]. In the study of lightly cooked foods, $18 \%$ were of borderline and $12 \%$ were of unsatisfactory microbiological quality, demonstrating an overall similar quality to that reported here for pâté. However, in contrast to the pâté study, 2\% (6 samples) of the lightly cooked foods were unsatisfactory and potentially injurious to health due to the presence of: Salmonella spp. (one duck breast); Campylobacter spp. (two pink duck breast and one chicken liver pâté); L. monocytogenes at $4.3 \times 10^{3}$ $\mathrm{cfu} / \mathrm{g}$ (one duck confit with foie gras ballotine) or $C$. perfringens at $2.5 \times 10^{5} \mathrm{cfu} / \mathrm{g}$ (chicken liver pâté; [26]). The results from these two studies, together with epidemiological evidence already presented from reported outbreaks, reconfirms the potential public health risks from liver pâté both from Salmonella and Campylobacter when lightly or under cooked and from L. monocytogenes when conditions allowed multiplication. A study in 2014 reviewed pâté manufacturing recipes, as well as identifying procedures likely to eliminate, or at least reduce, the presence of Campylobacter, and included washing livers with organic acids, freeze thawing and flambé in alcohol [1]. Furthermore the Food Standards Agency has provided advice including a liver pâté recipe 'for caterers that's free from the bacteria Campylobacter' [37]. A study in 2012-13 of chicken liver on retail sale detected Campylobacter in $87 \%$ with a level of contamination up to $>10000 \mathrm{cfu} / \mathrm{g}$ [32]. At the time of writing (2016) efforts by the poultry industry have shown some reduction in the levels of Campylobacter contamination on the surface of chickens at retail [38]. However, it is not known if this reduction has also been reflected in the presence and levels of contamination in chicken livers. Furthermore a study in 2015 showed a tendency for both chefs and the general public to undercook liver [39] and although the highest numbers of campylobacteriosis outbreaks associated with consumption of poultry liver pâté were reported in England in 2010, these have continued to be reported 
each year up to 2016 (PHE unpublished data) demonstrating a continuing public health risk.

In summary, we report here results of a study on the microbiological quality of 870 liver pâté samples on sale in catering and retail premises in England during 2012-13. Seventy-three percent of samples were of satisfactory microbiological quality, $18 \%$ were borderline and $9 \%$ were unsatisfactory. Although the presence of pathogens in this study was rare, there are continued risks of contamination of this food product with levels of this bacterium which are unsatisfactory and potentially injurious to health. There is therefore a continued need to control microbiological hazards in this food type including by maintaining adequate cooking regimes and high standards of hygiene to prevent cross-contamination.

\section{ACKNOWLEDGEMENTS}

This research did not receive any specific grant from funding agencies in the public, commercial or not-for-profit sectors. The authors thank the staff in Environmental Health Departments throughout England and staff in the PHE Food, Water and Environmental Microbiology Laboratories for their contributions to this study. They also thank Dr Kathie Grant of the PHE Gastrointestinal Bacteria Reference Unit, for discussion on data on the typing of L. monocytogenes isolates and Lukeki Kaindama and Richard Elson from the PHE Gastrointestinal, Emerging and Zoonoses Infections for provision of e-FOSS outbreak data.

\section{DECLARATION OF INTERESTS}

None.

\section{REFERENCES}

1. Hutchison M, et al. A method for the preparation of chicken liver pâté that reliably destroys campylobacters. International Journal Environmental Research and Public Health 2015; 12: 4652-4669.

2. McLauchlin J, et al. Human listeriosis and pâté: a possible association. British Medical Journal 1991; 303: 773-775.

3. Threlfall EJ, Hall ML, Rowe B. Salmonella gold-coast from outbreaks of food-poisoning in the British Isles can be differentiated by plasmid profiles. Journal of Hygiene (London) 1986; 97: 115-122.

4. Little CL, et al. A recipe for disaster: outbreaks of campylobacteriosis associated with poultry liver pâté in
England and Wales. Epidemiology and Infection 2010; 138: 1691-1694.

5. Wensley A, Coole L. Cohort study of a dual-pathogen point source outbreak associated with the consumption of chicken liver pâté, UK, October 2009. Journal of Public Health 2013; 35: 585-589.

6. Edwards DS, et al. Campylobacteriosis outbreak associated with consumption of undercooked chicken liver pâté in the East of England, September 2011: identification of a dose-response risk. Epidemiology and Infection 2014; 142: 352-357.

7. Parry A, Fearnley E, Denehy E. 'Surprise': outbreak of Campylobacter infection associated with chicken liver pâté at a surprise birthday party, Adelaide, Australia, 2012. Western Pacific Surveillance and Response Journal 2012; 3: 16-19.

8. Scott MK, et al. Notes from the field: campylobacteriosis outbreak associated with consuming undercooked chicken liver pâté-Ohio and Oregon, December 2013-January 2014. Morbidity and Mortality Weekly Report 2015; 64: 399.

9. Moffatt CRM, et al. A large outbreak of Campylobacter jejuni infection in a university college caused by chicken liver pâté, Australia, 2013. Epidemiology and Infection 2016; 144: 2971-2978.

10. Lahti E, et al. Confirmation of a campylobacteriosis outbreak associated with chicken liver pâté using PFGE and WGS. Zoonoses Public Health 2017; 64: 14-20.

11. Lafuente S, et al. Two simultaneous botulism outbreaks in Barcelona: Clostridium baratii and Clostridium botulinum. Epidemiology and Infection 2013; 141: 19931995.

12. Schwarz NG, et al. A food-borne outbreak of hepatitis A virus (HAV) infection in a secondary school in Upper Normandy, France, in November 2006. Euro Surveillance 2008; 13. pii: 18885.

13. Krovacek K, et al. Isolation and virulence profiles of Aeromonas hydrophila implicated in an outbreak of food poisoning in Sweden. Microbiology and Immunology 1995; 39: 655-661.

14. Elson R, et al. Microbiological examination of ready-to-eat cold sliced meats and pâté from catering and retail premises in the UK. Journal of Applied Microbiology 2004; 96: 499-509.

15. Food Standards Agency. Food Law Code of Practice. London: Guidance FSA, 2015. (https://www.food.gov. uk/sites/default/files/Food $\% 20$ Law $\% 20$ Practice $\% 20$ Guida nce $\% 20$ October $\% 202015 \% 20-\% 20$ FINAL $\% 20$.pdf). Accessed 16 December 2016.

16. Nogva HK, et al. Application of 5'-nuclease PCR for quantitative detection of Listeria monocytogenes in pure cultures, water, skim milk, and unpasteurized whole milk. Applied and Environmental Microbiology 2000; 66: 4266-4271.

17. Doumith M, et al. Differentiation of the major Listeria monocytogenes serovars by multiplex PCR. Journal of Clinical Microbiology 2004; 42: 3819-3822.

18. Vitullo M, et al. Real-time PCRs assay for serogrouping Listeria monocytogenes and differentiation from other 
Listeria spp. Molecular and Cellular Probes 2013; 27: 68-70.

19. Roussel S, et al. Fluorescence amplified fragment length polymorphism compared to pulsed field gel electrophoresis for Listeria monocytogenes sub-typing. BMC Microbiology 2013; 13: 14. (http://www.biomedcentral. com/1471-2180/13/14).

20. Health Protection Agency. Guidelines for Assessing the Microbiological Safety of Ready-to-Eat Foods Placed on the Market. London: HPA, 2009. (https://www.gov. uk/government/uploads/system/uploads/attachment_data/ file/363146/Guidelines_for_assessing_the_microbiological_ safety_of_ready-to-eat_foods_on_the_market.pdf). Accessed 16 August 2016.

21. European Commission Regulation (EC). No. 2073/2005 on microbiological criteria for foodstuffs. 2005. (http:// eur-lex.europa.eu/legal-content/EN/TXT/PDF/?uri=CE LEX:32005R2073\&from=en). Accessed October 2016.

22. Nichols G, McLauchlin J, de Louvois J. The contamination of pâté with Listeria monocytogenes - results from the 1994 European Community-Coordinated Food Control Program for England and Wales. Journal of Food Protection 1998; 61: 1299-1304.

23. Little CL, Omotoye R, Mitchell RT. The microbiological quality of ready-to-eat foods with added spices. International Journal of Environmental Health Research 2003; 13: 31-42.

24. McLauchlin J, et al. An assessment of the microbiological quality of meat-pies from retail sale in England 2013. Journal of Food Protection 2016; 79: 781-788.

25. Sagoo SK, et al. Assessment of the microbiological safety of dried spices and herbs from production and retail premises in the United Kingdom. Food Microbiology 2009; 26: 39-43.

26. Jørgensen F, et al. An assessment of the microbiological safety of lightly cooked food from retail premises in the United Kingdom. Epidemiology and Infection 2017. doi: 10.1017/S0950268817000048.

27. Gilbert RJ, McLauchlin J, Velani SK. The contamination of paté by Listeria monocytogenes in England and Wales in 1989 and 1990. Epidemiology and Infection 1993; 110: 543-551.

28. Uyttendaele M, et al. Evaluation of a challenge testing protocol to assess the stability of ready-to-eat cooked meat products against growth of Listeria monocytogenes. International Journal of Food Microbiology 2004; 90: 219-236.

29. Awofisayo-Okuyelu A, et al. An outbreak of human listeriosis in England between 2010 and 2012 associated with consumption of pork pies. Journal of Food Protection 2016; 79: 732-740.

30. Rodrigo S, et al. Occurrence of selected foodborne pathogens on poultry and poultry giblets from small retail processing operations in Trinidad. Journal of Food Protection 2006; 69: 1096-1105.

31. Noormohamed A, Fakhr MK. Incidence and antimicrobial resistance profiling of Campylobacter in retail chicken livers and gizzards. Foodborne Pathogens and Disease 2012; 9: 617-624.

32. Harrison D, et al. Freezing as an intervention to reduce the numbers of campylobacters isolated from chicken livers. Letters in Applied Microbiology 2013; 57: 206-213.

33. Messens W, et al. Estimating the public health impact of setting targets at the European level for the reduction of zoonotic Salmonella in certain poultry populations. International Journal of Environmental Research and Public Health 2013; 10: 4836-4850.

34. Swanenburg M, et al. Salmonella in slaughter pigs: prevalence, serotypes and critical control points during slaughter in two slaughterhouses. International Journal of Food Microbiology 2001; 70: 243-254.

35. Sofos JN. Challenges to meat safety in the 21 st century. Meat Science 2008; 78: 3-13.

36. Seo KS, Bohach GA. Staphylococcus aureus. In: Doyle MP, Beuchat LR, eds. Food Microbiology: Fundamentals and Frontiers, 3rd edn. Washington: ASM Press, 2007, pp. 493-518.

37. Food Standards Agency. A chicken liver pate recipe for caterers that's free from the bacteria Campylobacter. Undated. (https://www.food.gov.uk/business-industry/gui dancenotes/hygguid/chicken-liver-pate-recipe). Accessed October 2016.

38. Food Standards Agency. Campylobacter contamination in fresh whole chilled UK-produced chickens at retail: January - March 2016: 2016. (http://www.food.gov.uk/ sites/default/files/campy-survey-report-jan-mar-2016.pdf). Accessed October 2016.

39. Jones AK, et al. Restaurant cooking trends and increased risk for Campylobacter infection. Emerging Infectious Diseases 2016; 22: 1208-1215. 